\title{
General review
}

\section{Use of artesunate in non-malarial indications}

\author{
L'artésunate en dehors du paludisme \\ A. Raffetin ${ }^{\text {a }}$, F. Bruneel ${ }^{\text {b }}$, C. Roussel ${ }^{\mathrm{c}}$, M. Thellier ${ }^{\mathrm{d}, \mathrm{e}}$, P. Buffet $^{\mathrm{c}, \mathrm{d}}$, E. Caumes $^{\mathrm{f}, \mathrm{g}}$, \\ S. Jauréguiberry ${ }^{\mathrm{d}, \mathrm{f}, \mathrm{g}, *}$ \\ ${ }^{a}$ Service de maladies infectieuses et tropicales et de médecine interne, CHI Lucie-et-Raymond-Aubrac, 94190 Villeneuve Saint-Georges, France \\ ${ }^{\mathrm{b}}$ Service de réanimation médicale, centre hospitalier de Versailles, hôpital André-Mignot, 78150 Le Chesnay, France \\ ${ }^{\mathrm{c}}$ Inserm, unité biologie intégrée du globule rouge, laboratoire d'excellence GR-Ex, Sorbonne universités, université Paris Descartes, INTS, 75015 Paris, France \\ ${ }^{\mathrm{d}}$ Centre national de référence pour le paludisme, 75013 Paris, France \\ e Service de parasitologie-mycologie, groupe hospitalier Pitié-Salpêtrière, AP-HP, 75013 Paris, France \\ ${ }^{\mathrm{f}}$ Service des maladies infectieuses et tropicales, groupe hospitalier Pitié-Salpêtrière, AP-HP, 75013 Paris, France \\ ${ }^{\mathrm{g}}$ Inserm, institut Pierre-Louis d'épidémiologie et de santé publique (UMRS 1136), Sorbonne universités, UPMC université Paris 06, 75013 Paris, France
}

\begin{abstract}
Introduction. - Artesunate and other artemisinin derivatives are used in various infectious and non-infectious diseases. We aimed to analyze available data on artesunate and artemisinin derivatives activity in humans and their potential clinical benefits in non-malarial indications.

Material and methods. - Literature review performed on PubMed and the Cochrane Library databases using the PRISMA method. We analyzed studies published in English from January 2008 to August 2017 using the same indicators of drug efficacy.

Results. - We included 19 studies performed in humans (1 meta-analysis, 1 literature review, 4 randomized controlled trials, 3 prospective controlled trials, 3 prospective uncontrolled trials, 2 exploratory phase 1 or 2 trials, 1 case series, and 4 case reports). Artesunate and artemisinin derivatives demonstrated efficacy in the treatment of schistosomiasis in combination with praziquantel $(P=0.003)$. Artesunate monotherapy was less effective than praziquantel alone $(P<0.001)$ probably because its activity only affects the early stages of Schistosoma parasites. Artesunate monotherapy could be interesting as a chemoprophylactic drug against schistosomiasis $(P<0.001)$. Findings seem promising but are still controversial in the treatment of multidrug-resistant CMV infections. Studies do not conclude on artesunate and artemisinin derivatives efficacy in the treatment of cervix, breast, colorectal, and lung cancers.

Conclusion. - Artesunate and artemisinin derivatives in combination with praziquantel were effective against schistosomiasis, and could be used as a chemoprophylactic drug alone. They could be interesting as anti-CMV and anti-tumor treatment. Additional trials in humans are required to assess the efficacy of artesunate and artemisinin derivatives in diseases other than malaria.
\end{abstract}

Keywords: Artesunate; Parasitic diseases; Viral diseases; Cancer

\section{Résumé}

Introduction. - L'artésunate et les autres dérivés d'artémisinine sont les traitements de première ligne du paludisme. L'objectif était d'analyser les données disponibles de l'utilisation de l'artésunate et des dérivés d'artémisinine chez l'homme dans d'autres pathologies infectieuses et non infectieuses.

Matériels et méthodes. - Une revue systématique de littérature a été conduite sur PubMed et Cochrane Library, selon une méthodologie PRISMA. Nous avons analysé toutes les études publiées en anglais entre janvier 2008 et août 2017.

\footnotetext{
* Corresponding author at: Service des maladies infectieuses et tropicales, groupe hospitalier Pitié-Salpêtrière, AP-HP, 75013 Paris, France.

E-mail address: stephane.jaureguiberry @ aphp.fr (S. Jauréguiberry).
} 
Résultats. - Nous avons inclus 19 études (1 méta-analyse, 1 revue de littérature, 4 essais randomisés contrôlés, 6 essais prospectifs contrôlés et non contrôlés, 2 essais de phase 1 ou 2, 1 série de cas et 4 rapports de cas). L'artésunate et les autres dérivés d'artémisinine ont montré une efficacité dans le traitement de la schistosomose en combinaison avec le praziquantel $(p=0,003)$. L'artésunate en monothérapie est moins efficace que le praziquantel seul $(p<0,001)$. L'artésunate en monothérapie pourrait être utilisé comme agent prophylactique de la schistosomose $(p<0,001)$. Des données d'efficacité, quoique controversées, semblent intéressantes dans le traitement de l'infection à CMV résistant. Les travaux publiés ne permettent pas de conclure à une efficacité dans le cancer du col de l'utérus, du sein, du carcinome colorectal et cancers pulmonaires.

Conclusion. - L'artésunate et autres dérivés d'artémisinine en combinaison avec le praziquantel sont efficaces contre la schistosomose. Ils pourraient être intéressants comme agent anti-CMV et possiblement comme agent antitumoral. Cependant, les travaux publiés ne permettent pas de positionner ces traitements dans d'autres pathologies que le paludisme.

Mots clés : Artésunate ; Infections parasitaires ; Infections virales ; Cancers

\section{Introduction}

More than 1,600 years ago, Ge Hong (284-346 CE) described the medicinal herb Artemisia annua for the treatment of "marsh fever". In the 1970s, the Chinese project 523 led by $\mathrm{Pr} \mathrm{Tu}$ Youyou isolated a non-toxic extract of $A$. апnua, which induced $100 \%$ parasite clearance in animal models of malaria (Plasmodium berghei and P. cynomolgi) [1]. The active component of this extract, artemisinin, was identified in 1972. Its stereostructure (Sesquiterpene lactones) was identified in 1975. Studies conducted in humans in the 1980-90s led to recommending artemisinin and its derivatives in the first-line treatment of malaria: oral artemisinin-based combination therapy for the treatment of uncomplicated malaria, and parenteral artesunate for the treatment of severe malaria [2-4]. New artemisinin-like ozonides are being investigated as a way to cope with the emergence of artemisinin-resistant $P$. falciparum, and to treat diseases other than malaria. Nonetheless, the mechanisms of action of artesunate and artemisinin derivatives on plasmodial species are not extensively studied and are still controversial $[5,6]$. The oxidative and metabolic stress triggered by the cleavage of the endoperoxide bond by ferrous heme is the major mechanism of parasite killing.

In in vitro and animal models, artesunate presents broad antiparasitic effects (Schistosoma sp., Fasciola hepatica, Babesia sp., etc.), strong anti-infectious effects (cytomegalovirus, Ebola, etc.), and anti-tumor, anti-inflammatory, anti-oxidant, anti-angiogenesis, and immunomodulatory effects [7,8]. However, artesunate and artemisinin derivative activities in vitro and in humans are different and results must be interpreted cautiously as their half-lives and dosages vary.

The aim of this study was to analyze available data on artesunate and artemisinin derivative activity in humans and their potential clinical benefits in non-malarial indications.

\section{Material and methods}

We consulted PubMed and the Cochrane Library databases, and used the PRISMA method to conduct this literature review [9].
We included randomized or non-randomized studies published in English from January 2008 to August 2017 performed in humans in controlled or uncontrolled groups. We used the same indicators of drug efficacy between the compared groups. We included meta-analyses and literature reviews, two exploratory phase 1 or 2 trials, case series, and relevant case reports. We used the MeSH terms "artemisinin", "Schistosoma", "Fasciola", "Leishmania", "cytomegalovirus", "Ebola virus", "Borrelia", "lung cancer", "breast cancer", "colorectal cancer", and "cervix cancer". To introduce these studies performed in humans, we present the most relevant in vitro and animal studies that preceded.

\section{Results}

\subsection{Confirmed mechanisms of action of artesunate and artemisinin derivatives in infectious diseases other than malaria in humans}

The most common underlying mechanisms of action of artemisinin derivatives seem to be the oxidative and the metabolic stress as described for $P$. falciparum, responsible for cell damages and the death of the infectious agents [10].

\subsubsection{Anti-parasitic action of artemisinin derivatives}

Artemisinin derivatives have a wide range of anti-parasitic activity, only demonstrated in in vitro or animal models, against Trypanosoma spp., Toxoplasma gondii, F. hepatica, Babesia spp., Acanthamoeba castellanii, Naegleria fowleri, and Echinococcus spp. [7,8,10].

Few studies (Table 1) have been performed in humans to assess the efficacy of artemisinin derivatives against Schistosoma spp. $(n=4)$, Leishmania spp. $(n=1)$, and $F$. hepatica $(n=1)$.

Schistosomiasis is a helminthic disease affecting more than 200 million people in the tropics as well as travelers. Treatment mainly relies on a single drug, praziquantel, for the chronic stage of the disease. Praziquantel cannot kill schistosomula at the invasive stage of the disease. This results in frequent treatment failures [11]. Artemisinin derivatives were active against schistosomula in in vitro and animal models, and a combination 
Table 1

Artesunate and artemisinin derivative activities in human parasitic infections (apart from antimalarial activity).

Activité de l'artésunate et des dérivés d'artémisinine au cours d'infections parasitaires chez l'homme (activité anti-plasmodiale mise à part).

\begin{tabular}{|c|c|c|c|c|c|}
\hline $\begin{array}{l}\text { Artesunate } \\
\text { action }\end{array}$ & Type of article & Author, Date & Study design & Results & Limitations \\
\hline $\begin{array}{l}\text { Schistosoma } \\
\text { spp. }\end{array}$ & Meta-analysis & $\begin{array}{l}\text { Pérez del } \\
\text { Villar et al., } \\
2012 \text { [18] }\end{array}$ & $\begin{array}{l}24 \text { randomized trials included comparing: the } \\
\text { therapeutic efficacy of oral artesunate alone, } \\
\text { artesunate + sulfadoxine-pyrimethamine, and } \\
\text { a combination of artemisinin } \\
\text { derivatives + praziquantel against } \\
\text { praziquantel alone on schistosomiasis; } \\
\text { diagnostic criteria: Kato-Katz thick smears } \\
\text { (S. mansoni and } S \text {. japonicum) or filtration of } \\
\text { urine ( } \text {. haematobium); primary outcome } \\
\text { measure: parasitological cure (absence of eggs } 3 \\
\text { to } 8 \text { weeks after treatment); and the preventive } \\
\text { efficacy of artesunate and artemether against } \\
\text { placebo, administered at } 1 \text { or } 2 \text {-week intervals } \\
\text { up to } 13 \text { doses in healthy villagers during the }\end{array}$ & $\begin{array}{l}\text { Schistosomiasis treatment: = > artesunate } \\
\text { alone }<\text { praziquantel alone; artesunate- } \\
\text { sulfadoxine-pyrimethamine }<\text { praziquantel } \\
\text { alone; artemisinin } \\
\text { derivatives + praziquantel }>\text { praziquantel } \\
\text { alone; artesunate alone }(4 \mathrm{mg} / \mathrm{kg} / \text { day for } 3 \text { days) } \\
\text { is less effective than praziquantel }(40 \mathrm{mg} / \mathrm{kg} \\
\text { once) }(\mathrm{OR}=0.27 \text { [ } 95 \% \mathrm{CI} 0.13-0.53 \text {; } \\
P<0.001]) \text { artesunate }(4 \mathrm{mg} / \mathrm{kg} / \mathrm{day} \text { for } 3 \\
\text { days })+ \text { sulfadoxine-pyrimethamine } \\
(250 \mathrm{mg} / 12.5 \mathrm{mg} \text { for } 3 \text { days or } 25 \mathrm{mg} \text { for } 1 \text { day) } \\
\text { is less effective than praziquantel }(40 \mathrm{mg} / \mathrm{kg} / \mathrm{day} \\
\text { once) }(\mathrm{OR}=0.14 \text { [ } 95 \% \mathrm{CI} 0.02-0.92 ; P=0.04]) \text {; } \\
\text { artemisinin (artesunate } 4 \mathrm{mg} / \mathrm{kg} / \mathrm{day} \text { for } 3 \text { days }\end{array}$ & $\begin{array}{l}\text { Results were compared in various } \\
\text { populations } \\
\text { Small sample size } \\
\text { Lack of studies reporting the efficacy of } \\
\text { artemisinin derivatives as prophylactic } \\
\text { drugs in } S \text {. mansoni and } \text { S. haematobium } \\
\text { infections (mainly in } S \text {. japonicum } \\
\text { infections) } \\
\text { Studies published in Chinese were } \\
\text { excluded whereas many studies have } \\
\text { been published in this language on } \\
\text { artemisinin derivatives used as } \\
\text { prophylaxis in } S \text {. japonicum } \\
\text { schistosomiasis }\end{array}$ \\
\hline
\end{tabular}
high transmission period ( 2 to 6 months) in or artemether $6 \mathrm{mg} / \mathrm{kg}$ once) + praziquantel endemic areas; diagnostic criteria: please see $\quad(40 \mathrm{mg} / \mathrm{kg}$ once or $3 \times 20 \mathrm{mg} / \mathrm{kg}$ for 1 day or 6 above; primary outcome measure: infection rate days) showed a higher cure rate than (number of patients infected with Schistosoma praziquantel monotherapy with OR $=2.07$ (95\% spp. against total number of included patients, 3 to 4 weeks after treatment)

CI $1.27-3.36 ; P=0.003$ )

Schistosomiasis prophylaxis: artesunate or

\section{artemether $>$ placebo}

Artesunate $(6 \mathrm{mg} / \mathrm{kg}$ once $)(\mathrm{RR}=0.11[95 \% \mathrm{Cl}$

$0.06-0.22 ; P<0.001])$ or artemether $(6 \mathrm{mg} / \mathrm{kg}$ once) $(\mathrm{RR}=0.25[95 \% \mathrm{CI} 0.16-0.40$

$P<0.001])>$ placebo

Literature $\quad$ Saeed et al., $\quad 3$ randomized trials and 3 meta-analyses

review 2016 [13] comparing the efficacy of artemisinin derivatives and praziquantel in the treatment of

schistosomiasis were included

Artesunate alone is less effective than

praziquantel alone

Artesunate and praziquantel in combination

seem to be more effective that praziquantel

alone

To assess the efficacy and tolerability of the

controlled trial 2014 [19] treatments against $S$. haematobium in school-aged children $(n=61)$ in Ivory Coast: praziquantel ( $40 \mathrm{mg} / \mathrm{kg}$ once); mefloquine $(25 \mathrm{mg} / \mathrm{kg})$ combined with praziquantel ( $40 \mathrm{mg} / \mathrm{kg}$ once); mefloquine-artesunate (250mg-100 mg for 3 days) combined with praziquantel $(40 \mathrm{mg} / \mathrm{kg}$ once) Primary outcome measure: CR and ERR (urine samples collected before, on Days 21-22 and Days 78-79 after the first dosing, and filtrated to detect the eggs)
No statistical difference in efficacy was observed between the three treatment groups at each follow-up (days 21-22 and days 78-79) Day 21-22 post-treatment follow-up: $\mathrm{CR}=33 \%$ (95\% CI 11-55) for praziquantel, $29 \%$ (95\% C $8-50)$ for mefloquine-artesunate-praziquantel, and $26 \%$ (95\% CI 5-48) for

mefloquine-praziquantel; and ERR $>94 \%$ for all Day 78-79 post-treatment follow-up: $\mathrm{CR}=19 \%$ (praziquantel) to $33 \%$

(mefloquine-artesunate-praziquantel), and ERR $>90 \%$. Praziquantel monotherapy was the best tolerated treatment

(mefloquine-artesunate-praziquantel group: 91\% of mild adverse events; mefloquine-praziquantel group: $95 \%$ of mild adverse events)
No description of the methodology of this review

The authors did not distinguish studies evaluating the efficacy of artesunate as a curative treatment of schistosomiasis from studies evaluating artesunate as a prophylactic treatment

The viability of excreted eggs was not determined. Counts of dead eggs might have been included in the analysis, and the reported cure rates might underestimate the true situation. It is therefore impossible to draw any conclusion 
Table 1 (Continued)

\begin{tabular}{|c|c|c|c|c|c|}
\hline Artesunate & Type of article & Author, Date & Study design & Results & Limitations \\
\hline & Case report & $\begin{array}{l}\text { Martinez- } \\
\text { Calle et al., } \\
2013 \text { [22] }\end{array}$ & $\begin{array}{l}\text { A } 26 \text {-year-old patient presenting with an } \\
\text { imported acute schistosomiasis empirically } \\
\text { treated as malaria with artesunate }(4 \mathrm{mg} / \mathrm{kg} / \mathrm{day} \\
\text { for } 1 \text { day then } 2 \mathrm{mg} / \mathrm{kg} / \text { day for } 2 \text { days) in Mali. } \\
\text { Returning from Mali, the patient presented with } \\
\text { eosinophilia, negative urine microscopy, and late } \\
\text { seroconversion to S. haematobium ( } 7.5 \text { months). } \\
\text { A cystoscopy was performed, and the } \\
\text { microscopic examination of the urine identified } \\
\text { Schistosomiasis haematobium. Treatment with } \\
\text { praziquantel }\end{array}$ & $\begin{array}{l}\text { The patient became asymptomatic without } \\
\text { eosinophilia and with a negative urine } \\
\text { microscopy, after praziquantel treatment. This } \\
\text { case report suggests that artesunate used with } \\
\text { a malaria treatment protocol is partially } \\
\text { effective during the invasive stage of } \\
\text { schistosomiasis }\end{array}$ & $\begin{array}{l}\text { Other studies using artesunate or } \\
\text { artemisinin derivatives with various } \\
\text { treatment protocols during acute } \\
\text { schistosomiasis are needed, as well as } \\
\text { studies performed with a larger sample } \\
\text { size }\end{array}$ \\
\hline $\begin{array}{l}\text { Fasciola } \\
\text { hepatica }\end{array}$ & $\begin{array}{l}\text { Exploratory } \\
\text { phase } 2 \text { trial }\end{array}$ & $\begin{array}{l}\text { Keiser et al., } \\
2011 \\
{[24]}\end{array}$ & $\begin{array}{l}\text { To assess the efficacy and safety of oral } \\
\text { artemether administered at: (i) } 6 \times 80 \mathrm{mg} \text { over } \\
3 \text { consecutive days, (ii) and } 3 \times 200 \mathrm{mg} \text { within } \\
24 \text { hours, in } 36 \text { Fasciola-infected individuals in } \\
\text { Egypt. Main outcome measure: CR and ERR } \\
\text { (multiple Kato-Katz thick smears before and } \\
\text { after treatment). In case of treatment failure: } \\
\text { triclabendazole }\end{array}$ & $\begin{array}{l}\text { Treatment with artemether } 6 \times 80 \mathrm{mg}: \mathrm{CR} 35 \% \text {; } \\
\text { EER } 63 \% \\
\text { Treatment with artemether } 3 \times 200 \mathrm{mg}: \mathrm{CR} 6 \% \text {; } \\
\text { EER } 0 \% \\
\text { Artemether was well tolerated. Artemether is } \\
\text { not effective to treat fascioliasis } \\
\text { Triclabendazole was highly effective }(10 \mathrm{mg} / \mathrm{kg} \\
\text { in } 16 \text { patients: } \mathrm{CR}=67 \%, \mathrm{ERR}=94 \% \text {; and } \\
20 \mathrm{mg} / \mathrm{kg} \text { in } 4 \text { patients: } \mathrm{CR}=75 \%, \mathrm{ERR}=96 \%)\end{array}$ & $\begin{array}{l}\text { A one-dose treatment of artemether may } \\
\text { be insufficient to obtain activity against } \\
\text { F. hepatica }\end{array}$ \\
\hline $\begin{array}{l}\text { Leishmania } \\
\text { spp. }\end{array}$ & $\begin{array}{l}\text { Prospective } \\
\text { controlled trial }\end{array}$ & $\begin{array}{l}\text { Adam et al., } \\
2009 \\
{[25]}\end{array}$ & $\begin{array}{l}\text { Double-blind controlled study comparing } \\
\text { arte- } \\
\text { sunate + sulfamethoxypyrazine/pyrimethamine } \\
(\mathbf{1 0 0} \mathbf{~ m g} \text { artesunate }+\mathbf{2 5 0} \mathbf{~ m g} / \mathbf{1 2 . 5} \mathbf{~ m g} \\
\text { sulfamethoxypyrazine/pyrimethamine }) \\
(\boldsymbol{n}=\mathbf{2 0}) \text { versus placebo }(\boldsymbol{n}=\mathbf{2 1}) \text { to treat } \\
\text { cutaneous leishmaniasis, during } 4 \text { consecutive } \\
\text { days and repeated } 4 \text { times with a free washout } \\
\text { interval of } 15 \text { days. Outcome measures: } \\
\text { clearance or diminution of lesions characterized } \\
\text { before treatment and after day } 36 \text { and day } 72 \text {. In } \\
\text { case of treatment failure or placebo: pentavalent } \\
\text { antimony gluconate }\end{array}$ & $\begin{array}{l}\text { No statistical difference in both groups } \\
(P>0.05) \text { : Healing rate in the arte- } \\
\text { sunate + sulfamethoxypyrazine/pyrimethamine } \\
\text { group: } 90 \% \text {; Healing rate of the placebo group: } \\
85.7 \% \\
\text { This high healing rate in both arms of the study } \\
\text { indicates an important role of the placebo. Arte- } \\
\text { sunate + sulfamethoxypyrazine/pyrimethamine } \\
\text { does not prove more effective to treat } \\
\text { cutaneous leishmaniasis than placebo }\end{array}$ & $\begin{array}{l}\text { Spontaneous healing of Leishmania spp. } \\
\text { is expected and well documented }\end{array}$ \\
\hline
\end{tabular}

CR: cure rate; ERR: egg reduction rate.

Bold in tables means important informations or results, to underline the informations or the results and to make easier to read the tables. 
of artemisinin derivatives and praziquantel showed synergistic effects [7,8,10,12-14]. In animal models, artemisinin derivatives strongly reduced total worm rates, worm eggs shedding, and egg-caused granuloma in the liver of host animals [13]. Interestingly, artemether, artesunate, and dihydroartemisinin were as active against praziquantel-resistant $S$. japonicum as against the sensitive strain, which shows great promises in the fight against praziquantel resistance $[15,16]$. The combination of artemether and hemin led to higher worm reduction rates than artemether alone [17]. A recent meta-analysis of studies performed in humans confirmed that:

- artemisinin derivatives used in combination with praziquantel have the potential to increase the cure rates in schistosomiasis treatment, with no significant difference between $S$. mansoni, S. haematobium, and S. japonicum;

- artesunate alone is less effective than praziquantel alone;

- repeated doses of artemisinin derivatives have a prophylactic effect, significantly reducing the incidence of Schistosoma japonicum infections compared with placebo [18].

This prophylactic effect could be explained by the potential efficacy of artemisinin derivatives against schistosomula. Keiser et al. [19] performed a randomized trial and demonstrated that the addition of mefloquine or mefloquine-artesunate does not increase the efficacy of praziquantel alone against chronic $S$. haematobium infection and that praziquantel alone was the best tolerated treatment. Artesunate monotherapy may not be beneficial because its activity only affects the early stages of the parasite. In contrast, praziquantel acts against the mature forms of the parasite, curing $60 \%$ to $90 \%$ of patients presenting with $S$. mansoni infections and $22 \%$ to $83 \%$ of patients presenting with S. haematobium infections [20,21]. Martinez-Calle et al. [22] reported a case of imported acute schistosomiasis with asymptomatic eosinophilia, with initial negative urine microscopy, empirically treated as malaria with artesunate. The late seroconversion showing $S$. haematobium (7.5 months later) is indicative of a partial effect of artesunate on the course of the disease. However, artesunate was unable to definitely cure the patient. Other studies are required to measure the efficacy of various treatment protocols with artesunate or artemisinin derivatives in acute schistosomiasis.

As artemisinin derivatives in combination with praziquantel seem promising to treat $S$. mansoni, S. japonicum, and $S$. haematobium infections additional clinical trials are required to elucidate the effect of these combinations. Artesunate alone as a prophylactic drug should be used with caution as $S$. japonicum resistance to artesunate has already been described in China after 10 years of use in the treatment and prevention of schistosomiasis and as the efficacy on schistosomula is still controversial [22,23].

Fascioliasis is an emerging zoonotic disease of considerable veterinary and public health importance, causing liver and biliary tract infections. Triclabendazole is the only drug available for treatment. In vitro studies and animal models have documented promising fasciocidal properties of artemisinin derivatives [8]. Only one study was performed in humans (phase 2 trial) and demonstrated that artemether, administered as malaria treatment, showed no or only little effect against fascioliasis, and hence could not represent an alternative to triclabendazole [24]. The role of artemether and other artemisinin derivatives as partner drug in combination chemotherapy remains to be elucidated [24].

Leishmaniasis manifests primarily as cutaneous leishmaniasis, mucocutaneous leishmaniasis, or visceral leishmaniasis, with the latter being fatal if left untreated. Current anti-leishmanial drugs include pentavalent antimonials, amphotericin B, paromomycin, pentamidine, and miltefosine, with toxic effects and emergence of resistance. A large number of in vitro and animal model studies have shown that artemisinin derivatives have an anti-leishmanial activity with limited adverse events [10]. Only one study was performed in humans and failed to demonstrate the efficacy of the combination of artesunate and sulfamethoxypyrazine-pyrimethamine to treat cutaneous leishmaniasis compared with placebo, as described in Table 1 [25].

\subsubsection{Antiviral activity of artesunate and artemisinin derivatives}

Artemisinin derivatives present a wide range of antiviral activities, proven in in vitro or animal models, against cytomegalovirus (CMV), hepatitis $\mathrm{B}$ virus, hepatitis $\mathrm{C}$ virus, HIV 1, Epstein-Barr virus, herpes simplex viruses 1 and 2 (HSV1 and HSV2), human herpes virus 6, polyomavirus, and Ebola virus $[7,8,26]$.

Few studies have been performed in humans to assess the efficacy of artesunate against HSV2 $(n=1), \operatorname{CMV}(n=5)$, and Ebola virus $(n=1)$ (Table 2).

One case report described an HSV2 infection resistant to aciclovir, penciclovir, and foscarnet in an immunocompromised patient who fully recovered after 30 days of oral artesunate (100 mg per day) [27].

CMV is a major cause of disease in immunocompromised individuals, including patients presenting with AIDS and transplant recipients. It is also a common cause of congenital infection. Artesunate has proved active against CMV in in vitro and animal models [8,26,28]. Such studies demonstrated the efficacy of artesunate against CMV, even against ganciclovirresistant CMV strains [8,28]. The in vitro combination of artesunate and conventional anti-CMV drugs seems to be an interesting strategy for the treatment of CMV infections to reduce toxicity and drug resistance development [29]. Moreover, artesunate does not target the viral DNA polymerase of CMV and its mechanisms of action rely on the inhibition of the central regulatory processes of CMV-infected cells (such as activation pathways dependent on $\mathrm{NF}-\kappa \mathrm{B}$ or $\mathrm{Sp} 1$ ). It thus interferes with critical host-cell type and metabolism requirements for CMV replication [26]. This is interesting as artesunate presents a lower toxicity than conventional anti-CMV drugs. Very few case reports and case series describing the clinical effects of artesunate on CMV infection are available, and they reported controversial results [30-33]. Some case reports of patients presenting with multidrug-resistant CMV infection demonstrated the efficacy of oral artesunate ( $100 \mathrm{mg}$ per day) for at least 30 days $[30,31,33]$. Two prospective controlled trials 
Table 2

Artesunate and artemisinin derivative activities in human viral and bacterial infections.

Activité de l'artésunate et des dérivés d'artémisinine au cours des infections virales et bactériennes chez l'homme.

\begin{tabular}{lllll}
\hline $\begin{array}{l}\text { Artesunate } \\
\text { action }\end{array}$ & Type of article & Author, Date & Study design & Results \\
\hline Antiviral & &
\end{tabular}

HSV2

Case report 2012 [27]

swabs and in the serum: HSV-2+).

Multidrug-resistant HSV2 was identified after

transient responses to valaciclovir, foscarnet,

and cidofovir. As the lesions did not disappear,

oral artesunate $(100 \mathrm{mg} / \mathrm{day})$ was introduced

To assess the efficacy of

artemether-lumefantrine $(n=164$, treated for compared with no treatment $(n=143)$ in Malian children presenting with fever. Urine samples were collected at Day 0, Day 3, and Day 14. CMV DNA was quantified using real-time PCR

Quantitative CMV DNA PCR performed on dried blood spots collected from 494 Ugandan children, who were randomized either to artesunate + amodiaquine or sulfadoxine-pyrimethamine + amodiaquine for acute malaria infection malaria) on CMV shedding in urines
Within 4 days of artesunate initiation, the lesions were less painful. After completing 30 days of artesunate treatment: complete resolution of the lesions and negative HSV2 PCR on perineal swab for the first time since the lesions had appeared 9 months before. A second and third reactivation of HSV2 also rapidly

responded to oral artesunate $(100 \mathrm{mg} /$ day $)$ with resolution of the lesions and a negative HSV PCR. No toxicity problem was observed with artesunate

Day 0 endpoint: $81 / 164$ case patients (49\%) and $88 / 143$ controls (62\%) shed CMV. Day 0 an day 3 viral loads were similar. Day 14 endpoint: median viral load of case patients $<$ controls (360 versus 720 copies $/ \mathrm{mL}$ or 2.56 versus 2.86 $\left.\log ^{10}\right), P=0.059$. Day 0 in high viral shedders $(>1,000$ copies $/ \mathrm{mL}$ ) showed significantly lower median viral load at Day 14 in case patients $(490$ copies $\left./ \mathrm{mL}, 2.69 \log ^{10}\right)$ than in controls $(1,200$ copies $\left./ \mathrm{mL}, 3.08 \log ^{10}\right), P=0.045$. $=>$ Among high virus shedders artemether-lumefantrine decreased urine viral load, but the effect was not observed when analysis of both high and low shedders was performed

CMV detection: in $11.4 \%$ of children prior to treatment and $10.7 \% 3$ days later $(P=0.70)$. Average quantity of CMV: $0.30 \log ^{10}$ copies/million cells, and higher on Day 3 than Day 0 (95\% CI 0.01-0.58, $P=0.041$ ). No measurable difference in either the frequency or quantity of CMV detected in blood between both arms

Two patients demonstrated a rapid 0.8-2.1 log viral load decline by Day 7 , with a viral decay half-live of 0.9-1.9 days

Four patients demonstrated a continuous viral growth during treatment

No adverse events were observed in treatmen courses of up to 28 days

A divergent antiviral efficacy was revealed, ranging from $43 \%$ to $90 \%$, which appeared to be primarily dependent on the virus baseline growth dynamic
Confounding factors: concomitan reduction in immunosuppression and a gradual rise in lymphocyte count Unknown mechanisms of action of artesunate in HSV2 infections Artesunate $(100 \mathrm{mg} /$ day $)$ administered for 30 days may result in adverse events such as anemia or neutropenia. Further studies are required to conclude on the efficacy and safety of artesunate in HSV2 infections

No control group of children shedding CMV without malaria treated with artemether-lumefantrine

High rates of CMV shedding in this population, questioning the reliability of the diagnostic methods

Only 3 days of artesunate combined with amodiaquine whereas with the

conventional treatment with ganciclovir the viral load of CMV in blood decrease slowly in transplant patients $\left(<0.5 \log ^{10}\right.$ copies/mL)

Maybe longer courses and higher doses than those used for malaria are required to decrease CMV viremia

Further dose escalation studies are required to examine the role of artesunate in the treatment of CMV infection in transplant recipients The small number of patients and the early discontinuation of artesunate in $4 / 6$ patients do not enable to conclude on artesunate antiviral efficacy in heavily viral load increase or decrease by $<0.5 \log$ DNA copies/ml) on days 7, 14, and 21 immunosuppressed patients 


\begin{tabular}{|c|c|c|c|c|c|}
\hline $\begin{array}{l}\text { Artesunate } \\
\text { action }\end{array}$ & Type of article & Author, Date & Study design & Results & Limitations \\
\hline & Case series & $\begin{array}{l}\text { Germi et al., } \\
2014 \text { [31] }\end{array}$ & $\begin{array}{l}\text { CMV strains resistant to ganciclovir, } \\
\text { cidofovir, and/or foscarnet were genotypically } \\
\text { and phenotypically characterized in two } \\
\text { hematopoietic stem cell transplant recipients and } \\
\text { three solid-organ transplant recipients presenting } \\
\text { with CMV disease. Oral artesunate ( } 80 \mathrm{mg} \text { to } \\
200 \mathrm{mg} / \text { day) was administered for } 1 \text { to } 7 \text { months }\end{array}$ & $\begin{array}{l}\text { Artesunate led to a favorable virological and } \\
\text { clinical response in three patients presenting } \\
\text { with mild CMV diseases (fever and neutropenia) } \\
\text { but was ineffective in two patients with fatal } \\
\text { CMV diseases with lung involvement in spite of } \\
\text { a decrease in the CMV DNA load in blood and } \\
\text { broncho-alveolar fluid. No severe adverse event } \\
\text { was observed. Artesunate may be useful in } \\
\text { treating mild CMV disease without organ } \\
\text { involvement due to multidrug-resistant CMV } \\
\text { strains }\end{array}$ & $\begin{array}{l}\text { Unknown exact mechanisms of action of } \\
\text { artesunate in CMV infections. It is also } \\
\text { known that there is a low level of } \\
\text { artesunate in animal lung tissues - } \\
\text { Artesunate dosage of } 100 \mathrm{mg} / \text { day in the } \\
\text { long term may result in severe adverse } \\
\text { events such as anemia and neutropenia. } \\
\text { Further studies are required to conclude } \\
\text { on the efficacy and safety of artesunate in } \\
\text { CMV infections }\end{array}$ \\
\hline & Case report & $\begin{array}{l}\text { Shapira et al., } \\
2008[30]\end{array}$ & $\begin{array}{l}\text { A } 12 \text {-year-old boy presented with a CMV } \\
\text { viremia after a stem cell transplantation. } \\
\text { Ineffective treatment with foscarnet }(60 \mathrm{mg} / \mathrm{kg} \\
\times 3 / \text { day). Then ineffective combination with } \\
\text { cidofovir }(5 \mathrm{mg} / \mathrm{kg} / \mathrm{week}) \text {, ganciclovir } \\
(5 \mathrm{mg} / \mathrm{kg} \times 2 / \mathrm{day}) \text { and IV immunoglobulins. } \\
\text { Then treatment with IV artesunate } \\
(\mathbf{1 0 0} \mathbf{~ m g} / \text { day) for } 30 \text { days initially administered } \\
\text { as a compassionate treatment. }\end{array}$ & $\begin{array}{l}\text { Rapid reduction in viral load (1.7-2.1 log } \\
\text { reduction at day } 7 \text {, viral half-life of } 0.9-1.9 \\
\text { days) and improved hematopoiesis } \\
\text { One recurrent episode of CMV viremia and } \\
\text { CMV retinitis on day } 346 \text { treated with IV } \\
\text { artesunate and intravitreal ganciclovir, allowing } \\
\text { for a sustained virological response (day 665) }\end{array}$ & $\begin{array}{l}\text { Unknown exact mechanisms of action of } \\
\text { artesunate in CMV infections } \\
\text { Artesunate dosage of } 100 \mathrm{mg} / \text { day } \\
\text { administered for } 30 \text { days may result in } \\
\text { severe adverse events such as anemia or } \\
\text { neutropenia. Further studies are required } \\
\text { to conclude on the efficacy and safety of } \\
\text { artesunate in CMV infections }\end{array}$ \\
\hline & & $\begin{array}{l}\text { Stuelher et al., } \\
2015 \text { [32] }\end{array}$ & $\begin{array}{l}\text { Multidrug-resistant } \mathbf{C M V} \text { emerged after } \\
\text { transient responses to ganciclovir, foscarnet, and } \\
\text { cidofovir in a CMV-seropositive recipient who } \\
\text { underwent allogeneic hematopoietic stem cell } \\
\text { transplantation from a CMV-seronegative donor. } \\
\text { Treatment with leflunomide }(20 \mathrm{mg} \times 2 / \text { day }) \\
\text { failed. Experimental treatment with } \\
\text { artesunate }(\mathbf{1 0 0} \mathbf{~ m g} \times \mathbf{2} / \text { day })+\text { maribavir } \\
(\mathbf{4 0 0} \mathbf{m g} \times \mathbf{2} / \text { day })\end{array}$ & $\begin{array}{l}\text { The viral load declined from } 75,000 \mathrm{IU} / \mathrm{mL} \\
\left(4.88 \log ^{10} \mathrm{IU} / \mathrm{mL}\right) \text { to } 8,500 \mathrm{IU} / \mathbf{m L}\left(\mathbf{3 . 9 3} \mathbf{l o g}^{\mathbf{1 0}}\right. \\
\mathbf{I U} / \mathbf{m L}) \text { within } \mathbf{1 4} \text { days. Artesunate was } \\
\text { withdrawn } 2 \text { weeks after initiation because of } \\
\text { orthostatic hypotension. Experimental } \\
\text { treatment using artesunate failed because of } \\
\text { adverse events } \\
\text { Re-transplantation from a CMV-seropositive } \\
\text { donor supported by adoptive transfer of } \\
\text { pp65-specific T-cells and maribavir was } \\
\text { followed by long-lasting suppression }\end{array}$ & $\begin{array}{l}\text { The early discontinuation of artesunate } \\
\text { does not enable to conclude on } \\
\text { artesunate antiviral efficacy } \\
\text { Artesunate dosage of } 200 \mathrm{mg} / \text { day may } \\
\text { result in severe adverse events such as } \\
\text { anemia or neutropenia. Further studies } \\
\text { are required to conclude on the efficacy } \\
\text { and safety of artesunate in CMV } \\
\text { infections }\end{array}$ \\
\hline Ebola virus & $\begin{array}{l}\text { Prospective } \\
\text { controlled trial }\end{array}$ & $\begin{array}{l}\text { Gignoux et al., } \\
2016 \text { [36] }\end{array}$ & $\begin{array}{l}\text { To estimate the risk ratio }(\mathbf{R R}) \text { for death } \\
\text { among patients presenting with confirmed Ebola } \\
\text { virus disease }(n=382) \text { who were prescribed } \\
\text { artesunate-amodiaquine }(n=71) \text {, as compared } \\
\text { with those who were prescribed } \\
\text { artemether-lumefantrine }(n=194) \text { and those } \\
\text { who were not prescribed any antimalarial drug } \\
(n=117)\end{array}$ & $\begin{array}{l}125 / 194 \text { patients }(64.4 \%) \text { in the } \\
\text { artemether-lumefantrine group died versus } 36 / 71 \\
\text { patients }(50.7 \%) \text { in the artesunate-amodiaquine } \\
\text { group. In adjusted analyses, the } \\
\text { artesunate-amodiaquine group had a } 31 \% \\
\text { lower risk of death than the } \\
\text { artemether-lumefantrine group (RR } \mathbf{0 . 6 9} \text {; } \\
\text { 95\% CI, 0.54-0.89), with a stronger effect } \\
\text { observed among patients without malaria }\end{array}$ & $\begin{array}{l}\text { Amodiaquine is active against Ebola } \\
\text { virus: these results do not enable to } \\
\text { conclude on the efficacy of artesunate } \\
\text { against Ebola virus disease } \\
\text { Artemether-lumefantrine may increase } \\
\text { the risk of death in patients presenting } \\
\text { with Ebola virus disease (e.g. } \\
\text { contraindication in patients with known } \\
\text { hypokalemia) }\end{array}$ \\
\hline $\begin{array}{l}\text { Antibacterial } \\
\text { Borrelia } \\
\text { burgdorferi s.l. }\end{array}$ & $\begin{array}{l}\text { Uncontrolled } \\
\text { prospective } \\
\text { pilot trial }\end{array}$ & $\begin{array}{l}\text { Puri et al., } \\
2017 \text { [45] }\end{array}$ & $\begin{array}{l}7 \text { patients with Lyme borreliosis included to } \\
\text { assess the efficacy of artesunate } \\
(20 \mathbf{~ m g} \times \mathbf{4} / \mathbf{d a y}) \text { in combination with } \\
\text { ceftriaxone on short-term memory outcomes. } \\
\text { Diagnostic criteria: serology (not specified); } \\
\text { treatment evaluation: self-report questionnaire } \\
\text { on short-term memory }\end{array}$ & $\begin{array}{l}\text { No significant reduction in the severity of } \\
\text { short-term memory difficulties }(P \simeq 0.08) \text { in } \\
\text { patients treated with artesunate }+ \text { ceftriaxone }\end{array}$ & $\begin{array}{l}\text { Stages and symptoms of Lyme } \\
\text { borreliosis, serology, self-report } \\
\text { questionnaire, and duration of treatment } \\
\text { not mentioned } \\
\text { Other concomitant medications not } \\
\text { evaluated }\end{array}$ \\
\hline
\end{tabular}

HSV2: type 2 Herpes Simplex Virus; CMV: cytomegalovirus; IV: intravenous; RR: Risk ratio; AE: Adverse events.

Bold in tables means important informations or results, to underline the informations or the results and to make easier to read the tables. 
were performed. The first trial reported a lower median viral load of CMV in the urine of patients treated for malaria with artemether-lumefantrine than in the urine of those who did not receive antimalarial treatment [34]. The second trial did not report any difference in the blood viral load of CMV in children treated with standard three-day artesunate-amodiaquine or sulfadoxine/pyrimethamine-amodiaquine [35]. Longer treatment courses and/or higher doses of artesunate than those routinely used for malaria may be required for an effective treatment of CMV infection. Further studies are required to assess the efficacy of artesunate against CMV in humans.

During the last Ebola epidemics (2014-2016), antimalarials were systematically prescribed to all patients presenting with Ebola virus disease. One study of 382 patients demonstrated that the artemether-amodiaquine group had a $31 \%$ lower risk of death than the artemether-lumefantrine group (RR 0.69; $95 \%$ CI 0.54-0.89) [36]. Nonetheless, amodiaquine is known for its anti-Ebola virus activity. This study therefore does not prove the activity of artemether against Ebola virus.

\subsubsection{Antifungal activity of artesunate and artemisinin derivatives}

No study in humans has been performed. Artemisinin derivatives showed in vitro activity against Cryptococcus neoformans, Candida albicans, and Aspergillus fumigatus [7,8]. A synergistic effect was reported in combination with miconazole for C. albicans and with itraconazole for A. fumigatus $[37,38]$.

\subsubsection{Antibacterial activity of artesunate and artemisinin derivatives}

Several studies conducted in animal models reported that artesunate could enhance the anti-MRSA (methicillin-resistant Staphylococcus aureus) and the anti-E. coli activity of betalactams by inhibiting the release of pro-inflammatory cytokines and by increasing antibiotic accumulation in the bacteria via inhibition of the multidrug efflux pump system AcrAB-TolC [39-42]. We did not find any study performed in humans.

An in vitro study demonstrated the activity of artemisinin against in vitro amoxicillin-induced round bodies of Borrelia burgdorferi but artemisinin presented high minimum inhibitory concentrations (MICs) in active forms of Borrelia [43]. Moreover, these round forms of Borrelia are only observed in vitro and not in vivo [44]. In Lyme borreliosis, a non-comparative pilot study conducted in seven patients did not report any significant reduction in the severity of short-term memory difficulties $(P \simeq 0.08)$ in patients treated with artesunate and ceftriaxone [45]. The diagnostic criteria of borreliosis, the disease stage and symptoms, and the self-report questionnaire were not reported. Moreover, these patients received many other medications poorly evaluated in clinical trials ( $\mathrm{N}$-acetylcysteine, cholestyramine, broccoli extract, artichoke extract, etc.) that represent confounding factors to evaluate artesunate efficacy. Therefore, this study does not enable to conclude on the efficacy of artemisinin in human Lyme borreliosis.

\subsection{Mechanisms of action of artesunate and artemisinin derivatives in non-infectious diseases}

\subsubsection{Anti-tumor activity of artesunate and artemisinin derivatives}

The in vitro activity of artesunate against tumor cells was confirmed by animal studies of glioblastoma, brain tumor, pituitary macroadenoma, esophageal cancer, breast cancer, colorectal cancer, lung cancer, cervix carcinoma, melanoma, pancreatic cancer, hepatocellular carcinoma, prostate cancer, ovarian cancer, and leukemia [7,8,46-51]. Its mechanisms of action are based on the cleavage of the endoperoxide bridge and its subsequent oxidative stress responsible for:

- the formation of free radicals;

- a cycle cell arrest in phase G0-G1;

- DNA damages;

- NF-kB signaling;

- apoptosis, autophagy, ferroptosis;

- angiogenesis inhibition;

- an effect on signal transduction pathways (e.g. TCTP which regulates cell cycle transition, apoptosis, calcium homeostasis, and cytoskeleton) [52].

The role of iron in artemisinin derivative activity has already been described above and is crucial for tumor cells that express significantly more transferrin receptor on their cell surface than normal cells [52-54]. It explains why artemisinin derivatives preferentially kill tumor cells rather than normal cells. It also indicates that ferrous iron and transferrin might boost artemisinin derivative cytotoxicity in a tumor-specific manner. For example, ferrous glycine sulfate enhanced artemisinin-induced cytotoxicity in most tumors, including cisplatin-resistant neck tumor, but adverse events were described [53,54]. Moreover, specific cytotoxicity of artemisinin towards colorectal cancer (CRC) cells can be enhanced with the addition of aminolevulinic acid (ALA), a clinically used heme synthesis precursor, to increase heme levels. This novel artemisinin/ALA combination therapy proved to be more effective than artemisinin monotherapy in a mouse xenograft CRC model [49]. To our knowledge, no study conducted in humans and assessing these combinations has been published.

Few studies have been performed in patients presenting with neoplastic diseases. Several case studies reported the efficacy of artemisinin derivatives administered as compassionate treatments for uveal melanoma, glioblastoma, prostatic cancer, hepatocellular carcinoma, breast cancer, and laryngeal squamous cell carcinoma [55]. Only four controlled trials [56-59] were conducted in lung, colorectal, breast, and cervix cancers (Table 3).

Zhang et al. [56] performed a randomized controlled trial and reported that artesunate could be used for the treatment of nonsmall cell lung cancer (NSCLC) in combination with vinorelbine and cisplatin as the disease control rate was higher than with standard chemotherapy alone, and the time to progression was longer. As the article was written in Chinese, we could not 
Artesunate and artemisinin derivative activities in human cancers.

Activité de l'artésunate et des dérivés d'artémisinine au cours des cancers chez l'homme.

\begin{tabular}{|c|c|c|c|c|c|}
\hline $\begin{array}{l}\text { Artesunate } \\
\text { action }\end{array}$ & Type of article & Author, Date & Study design & Results & Limitations \\
\hline Lung cancer & $\begin{array}{l}\text { Randomized } \\
\text { controlled trial }\end{array}$ & $\begin{array}{l}\text { Zhang et al., } \\
2008 \text { [56] }\end{array}$ & $\begin{array}{l}120 \text { case patients of advanced NSCLC randomly } \\
\text { divided into simple chemotherapy group } \\
\text { (control group, } \boldsymbol{n}=\mathbf{6 0} \text {, vinorelbine }\left(25 \mathrm{mg} / \mathrm{m}^{2}\right. \\
\mathrm{IV} \text {, day } 1 \text { and day } 8) \text { and cisplatin }\left(25 \mathrm{mg} / \mathrm{m}^{2} \mathrm{IV} \text {, }\right. \\
\text { from Day } 2 \text { to Day } 4 \text { ) and }\end{array}$ & $\begin{array}{l}\text { No significant differences in the short-term } \\
\text { survival rate, MST and 1-year survival rate } \\
\text { between the trial group and the control group } \\
(P>0.05) \text {. DCR of the trial group } \\
(\mathbf{8 8 . 2 \%})>\text { control group }(\mathbf{7 2 . 7 \%})(\boldsymbol{P}<\mathbf{0 . 0 5}) \text {. }\end{array}$ & $\begin{array}{l}\text { Article in Chinese. Abstract available in } \\
\text { English. No details on the methodology. } \\
\text { Results should be interpreted with } \\
\text { caution. Impossible to draw any } \\
\text { conclusion from this study }\end{array}$ \\
\hline
\end{tabular}

artesunate-chemotherapy group (trial group, TTP of the trial group ( 24 weeks) longer than $n=60$, same chemotherapy and artesunate

$(120 \mathrm{mg} /$ day IV, from day 1 to day 8$)$. Primary outcomes: short-term survival rate, DCR, TTP, MST, 1-year survival rate, toxicity, and safety

Breast cancer Uncontrolled Von Hagen phase I trial et al., 2017 $[58$

$\begin{array}{lll}\text { Colorectal } & \text { Randomized } & \text { Krishna et al. } \\ \text { cancer } & \text { controlled trial } & 2015[57]\end{array}$

Cervix carcinoma

$\begin{array}{ll}\text { Uncontrolled } & \text { Jansen et al., } \\ \text { prospective } & 2011[59]\end{array}$

Prospective, monocentric, open, uncontrolled,

phase I dose-finding study (optimal daily dose and safety of prolonged treatment) in patients $(n=23)$ presenting with advanced breast cancer: 100,150 , and $200 \mathrm{mg}$ ora artesunate/day as add-on therapy along with different guideline-based standard therapies Primary endpoints: type, number, intensity, and severity of DL-AEs possibly, probably, or certainly related to artesunate (NCI CTC-AE Version 3.0.). Secondary endpoints: response rates and clinical benefit (routine results, CA15-3, liver ultrasound)

Monocentric, randomized, double-blind,

placebo-controlled trial to compare the efficacy of artesunate $(200 \mathrm{mg} / \mathrm{day}$ for 14 days; $n=12$ with placebo $(n=11)$ in patients planned for curative resection of biopsy-confirmed single primary site CRC

Primary outcome measure: proportion of tumor cells undergoing apoptosis (significant if $>7 \%$ showed Tunel staining). Secondary outcomes: VEGF, EGFR, c-Myc, CD31, Ki67, and p53, and clinical responses

Open-label monocentric study to assess the safety and the potential clinical benefit of artenimol-R (hemi-succinate ester of artenimol) $(100 \mathrm{mg}$ to $200 \mathrm{mg} / \mathrm{day})$ in advanced cervix carcinoma ( $n=10$ patients). Primary outcomes: clinical symptoms, vaginal discharge and pain and tumor markers (immunohistochemistry on biopsies). Adverse events recorded the control group (20 weeks) $(P<0.05)$. No significant difference observed in toxicity between both groups, such as myelosuppression and digestion reaction $(P>0.05)$

Trial period of $4 \pm 1$ weeks.

Three patients experienced 6 DL-AEs

(leukopenia, neutropenia, asthenia, anemia) possibly related to artesunate. $\mathbf{U p}$ to $200 \mathrm{mg} / \mathbf{d a y}$ $(2.2-3.9 \mathrm{mg} / \mathrm{kg} / \mathrm{day})$ of oral artesunate were safe and well tolerated

Response assessment was not possible in eight patients (dose $100 \mathrm{mg}$ and $200 \mathrm{mg}$ ). Stable disease, considered as a clinical benefit, was

observed in 10 patients (dose $150 \mathrm{mg}$ and

$200 \mathrm{mg}$ ). The other assessable patients $(n=5)$ experienced progression

20 patients (artesunate $=9$, placebo $=11)$ completed the trial per protocol.

Apoptosis in $>7 \%$ of cells in artesunate group: $\mathbf{6 7 \%}$; in placebo group: $55 \%$ $(\boldsymbol{P}>\mathbf{0 . 0 5})$. Using Bayesian analysis, the probabilities of an artesunate treatment effect reducing Ki67 and increasing CD31 expression were 0.89 and 0.79, respectively. During a median follow up of 42 months, 1 patient in the artesunate and 6 patients in the placebo group developed recurrent CRC

Artenimol-R induced clinical remission in 2 patients for $>6$ months with a resolution of symptoms within 7 days. No adverse event of grade 3 or 4 occurred. The expression of $\mathrm{p} 53$ EGFR, and antigen Ki-67 (cellular marker of proliferation), and the number of blood vessels stained by the CD31 antibody decreased,

whereas the expression of transferrin receptor protein 1 (CD71) increased
Observational descriptive analysis in a very small number of patients; difficult to conclude on artesunate efficacy in breast cancer

Small sample size

Variability in quantitative

immuno-histochemical markers No informative pre-defined primary endpoint (proportion of patients with $>7 \%$ Tunel positive staining of tumor cells) after artesunate treatment: because of an unexpectedly high proportion (55\%) of placebo recipients? Only interpretable secondary endpoints

Very small sample size

Variability in quantitative

immuno-histochemical markers

Difficult to conclude on the efficacy of artesunate in cervix carcinoma

VEGF: vascular endothelial growth factor; IV: intravenous; DCR: disease control rate, TTP: time to progression, MST: mean survival time; DL-AEs: Dose-Limiting-Adverse Events, defined as clinically relevan

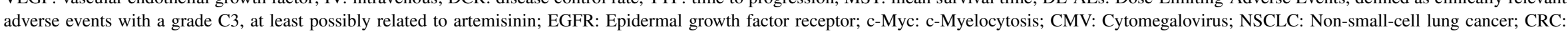
Colorectal cancer.

Bold in tables means important informations or results, to underline the informations or the results and to make easier to read the tables. 
analyze it in detail and it is impossible to draw a conclusion from these results.

Krishna et al. [57] performed a randomized placebocontrolled trial and demonstrated that artesunate had antiproliferative properties in colorectal cancer (reduction of the expression of Ki67, which is an important prognostic tumor marker in colorectal cancer). However, they could not conclude on the clinical efficacy as their first endpoint could not be interpreted. Artesunate was well tolerated.

Von Hagens et al. [58] performed a prospective, monocentric, open, uncontrolled, phase I, dose-finding study (optimal daily dose and safety of prolonged treatment) in patients $(n=23)$ presenting with advanced breast cancer. Oral artesunate was safe and well tolerated up to $200 \mathrm{mg} /$ day. Response assessment could not be performed for eight patients. Stable disease, considered as a clinical benefit, was however observed in 10 patients $(150 \mathrm{mg}$ and $200 \mathrm{mg}$ ). Progression was observed in the remaining assessable patients $(n=5)$.

Jansen et al. [59] reported an improvement in clinical symptoms (2/10 patients) and the good tolerability of Artenimol-R in 10 patients presenting with advanced carcinoma of the uterine cervix.

These trials do not enable to conclude on artesunate efficacy in lung, colorectal, breast, and cervix cancers due to methodological limitations (small samples, outcomes, etc.).

\subsubsection{Anti-inflammatory effect of artesunate and artemisinin derivatives}

Anti-inflammation is the third main effect of artemisinin derivatives. They are able to regulate innate and adaptive immunity in vitro and in vivo [60]. They significantly reduce the phagocytosis of macrophages and the in vivo phagocytic index, and they inhibit $\mathrm{TNF} \alpha$ production from macrophages (suppression of nuclear translocation of NF-кB) [39-42]. Besides suppressing pro-inflammatory cytokine production, artemisinin derivatives could also induce the anti-inflammatory cytokine production, such as IL-10 [61]. Artemisinin derivatives can suppress $\mathrm{T}$ cell activation and IL-2 production both in vitro and in vivo [62]. This latter study revealed that artemisinin derivatives (precisely SM934) could exhibit extensive protective effects in chronic inflammation conditions such as clinically effective corticosteroids. Several animal studies demonstrated a good effect on autoimmune diseases (arthritis, dermatitis, hepatic and pulmonary fibrosis, myasthenia gravis, colitis, encephalomyelitis, systemic lupus erythematous, etc.), allergic diseases (dermatitis and asthma), Alzheimer's disease, and atherosclerosis $[7,8,60,63,64]$. Only one study performed in humans $(n=90)$ reported that topical artesunate was effective against allergic dermatitis and photosensitive lesions (eczema, erythema multiforme, polymorphous light eruption, hygroa aestivale) and moderately effective against atopic dermatitis, psoriasis vulgaris, and dermatomyositis [65]. Unfortunately, we could only read the abstract as the article was not available in English and no detail was given on the study design and its methodology. Therefore we cannot draw any conclusion from this study.

\subsubsection{Anti-hemorrhagic activity of artesunate and artemisinin derivatives}

Subarachnoid hemorrhage (SAH) is a devastating cerebrovascular disease, responsible for a high morbidity and case fatality. In animal models, artesunate managed to preserve the blood-brain barrier integrity and improved neurological outcomes after $\mathrm{SAH}$ [7]. Its mechanisms of action are the activation of Claudin 3 and 5 (blood-brain barrier proteins forming tight junction), the inhibition of pro-inflammatory mediators in BV2 microglial cells, the inhibition of vascular smooth muscle cells, and the decrease in leukocyte adherence and accumulation in brain vessels (anti-ICAM1 activity, as in cerebral malaria) [7]. No study was performed in humans presenting with SAH or other cerebrovascular diseases such as intracerebral hemorrhage or ischemic cerebrovascular disease, intracranial aneurysm, or malformation, etc. Further studies are required to assess the efficacy of artesunate in these cerebrovascular diseases.

\section{Conclusion}

Artesunate and artemisinin derivatives are indicated as the first-line treatment of malaria. In humans, they demonstrated efficacy in the curative treatment of schistosomiasis but only in combination with praziquantel. Artesunate monotherapy may not be beneficial for patients presenting with chronic schistosomal disease. However, questions remain about the efficacy of artesunate during the invasive stage of the disease because its activity affects the early stages of the Schistosoma spp. parasite and artesunate could be efficient. Additional clinical trials are required to elucidate the effect of these combinations in various situations. Findings seem promising in the treatment of multidrug-resistant CMV with mild infections but data is scarce and still controversial. Artesunate and artemisinin derivatives could be interesting in cervix, breast, colorectal, and lung cancers, but the studies do not enable to draw any conclusion on their efficacy yet. Clinical studies are needed to assess the relevance of artemisinin derivatives both as anti-inflammatory and antihemorrhagic drugs. Finally, more trials in humans are required to assess the efficacy of artesunate and artemisinin derivatives in other diseases than malaria. No clear recommendation can be formulated so far.

\section{Contribution of authors}

AR performed the literature analysis and wrote the article. SJ supervised this work and reviewed the article.

FB, CR, MT, EC, and PB reviewed the article.

\section{Disclosure of interest}

Jauréguiberry déclare avoir des liens d'intérêts avec Sigma Tau pour des interventions ponctuelles et avoir des intérêts indirects avec Guilin et Walter Reed Army Institute.

Buffet, Roussel: intérêts indirects avec Guilin et Walter Reed Army Institute. 
Raffetin, Bruneel, Thellier, Caumes declare that they have no competing interest.

\section{References}

[1] Tu Y. The discovery of artemisinin (qinghaosu) and gifts from Chinese medicine. Nat Med 2011;17(10):1217-20.

[2] Dondorp A, Nosten F, Stepniewska K, Day N, White N, South East Asian Quinine Artesunate Malaria Trial (SEAQUAMAT) group. Artesunate versus quinine for treatment of severe falciparum malaria: a randomised trial Lancet 2005;366(9487):717-25.

[3] World Health Organization, editor. Guidelines for the treatment of malaria. 2nd ed Geneva: World Health Organization; 2010. p. 194.

[4] Société de Pathologie Infectieuse de Langue Française, Collège des Universitaires de Maladies Infectieuses et Tropicales, Société Française de Médecine des Armées, Société Française de Parasitologie, Société Française de Pédiatrie, Société Française de Médecine des Voyages, et al. Management and prevention of imported malaria (Revision 2017 of the 2007 Recommandations for clinical practice). Long text. Med Mal Infect 2017 [in press].

[5] Krishna S, Bustamante L, Haynes RK, Staines HM. Artemisinins: their growing importance in medicine. Trends Pharmacol Sci 2008;29(10):520-7.

[6] Ding XC, Beck H-P, Raso G. Plasmodium sensitivity to artemisinins: magic bullets hit elusive targets. Trends Parasitol 2011;27(2):73-81.

[7] Zuo S, Li Q, Liu X, Feng H, Chen Y. The potential therapeutic effects of artesunate on stroke and other central nervous system diseases. Bio Med Res Int 2016;2016:1-16.

[8] Ho WE, Peh HY, Chan TK, Wong WSF, Artemisinins:. pharmacological actions beyond anti-malarial. Pharmacol Ther 2014;142(1):126-39.

[9] Moher D, Liberati A, Tetzlaff J, Altman DG, PRISMA Group. Preferred reporting items for systematic reviews and meta-analyses: the PRISMA statement. J Clin Epidemiol 2009;62(10):1006-12.

[10] Loo CSN, Lam NSK, Yu D, Su X, Lu F. Artemisinin and its derivatives in treating protozoan infections beyond malaria. Pharmacol Res 2017;117:192-217.

[11] Jauréguiberry S, Paris L, Caumes E. Acute schistosomiasis, a diagnostic and therapeutic challenge. Clin Microbiol Infect 2010;16(3):225-31.

[12] Kong Q-M, Zhu X, Tong Q-B, Zheng B, Shi N-Y, Lou D, et al. Genomewide miRNAs expression profiles of Schistosoma japonicum schistosomula in response to artesunate. Pharmacogenomics 2016;17(18):2025-37.

[13] Saeed MEM, Krishna S, Greten HJ, Kremsner PG, Efferth T. Antischistosomal activity of artemisinin derivatives in vivo and in patients. Pharmacol Res 2016;110:216-26.

[14] Keiser J, Utzinger J. Artemisinins and synthetic trioxolanes in the treatment of helminth infections. Curr Opin Infect Dis 2007;20(6):605-12.

[15] Wang W, Li T-Y, Ji Y, Qu G-L, Qian Y-L, Li H-J, et al. Efficacy of artemether and artesunate in mice infected with praziquantel non-susceptible isolate of Schistosoma japonicum. Parasitol Res 2014;113(3):925-31.

[16] Wang W, AT Li H-J, Qu G-L, Xing Y-T, Yang Z-K, Dai J-R, et al. Is there a reduced sensitivity of dihydroartemisinin against praziquantel-resistant Schistosoma japonicum? Parasitol Res 2014;113(1):223-8.

[17] El-Lakkany NM, Seif El-Din SH. Haemin enhances the in vivo efficacy of artemether against juvenile and adult Schistosoma mansoni in mice. Parasitol Res 2013;112(5):2005-15.

[18] Pérez del Villar L, Burguillo FJ, López-Abán J, Muro A. Systematic review and meta-analysis of artemisinin based therapies for the treatment and prevention of schistosomiasis. PloS One 2012;7(9):e45867.

[19] Keiser J, Silué KD, Adiossan LK, N'Guessan NA, Monsan N, Utzinger J, et al. Praziquantel, mefloquine-praziquantel, and mefloquineartesunate-praziquantel against Schistosoma haematobium: a randomized, exploratory, open-label trial. PLoS Negl Trop Dis 2014;8(7):e2975.

[20] Danso-Appiah A, Olliaro PL, Donegan S, Sinclair D, Utzinger J. Drugs for treating Schistosoma mansoni infection. Cochrane Database Syst Rev 2013;2:CD280005

[21] Kramer CV, Zhang F, Sinclair D, Olliaro PL. Drugs for treating urinary schistosomiasis. Cochrane Database Syst Rev 2014;(8):CD000053.
[22] Martinez-Calle N, Pascual I, Rubio M, Carias R, Del Poso JL, Yuste JR. Asymptomatic Schistosoma haematobium infection in a traveler with negative urine microscopy and late seroconversion presumably linked to Artesunate. J Trav Med 2013;20(5):326-8.

[23] Hua H-Y, Liang Y-S, Zhang Y, Wei J-F, Guo H-X. The sensitivity of artesunate against Schistosoma japonicum decreased after 10 years of use in China. Parasitol Res 2010;107(4):873-8.

[24] Keiser J, Sayed H, el-Ghanam M, Sabry H, Anani S, el-Wakeel A, et al. Efficacy and safety of artemether in the treatment of chronic fascioliasis in Egypt: exploratory phase-2 trials. PLoS Negl Trop Dis 2011;5(9):e1285.

[25] Adam I, Hagelnur AA. Artesunate plus sulfamethoxypyrazine/pyrimethamine for the treatment of cutaneous leishmaniasis: a double-blind, placebo-controlled clinical trial. Int $\mathrm{J}$ Antimicrob Agents 2009;34(4):380-1.

[26] Efferth T, Romero MR, Wolf DG, Stamminger T, Marin JJG, Marschall M. The antiviral activities of artemisinin and artesunate. Clin Infect Dis 2008;47(6):804-11

[27] Sellar RS, Ward KN, Thomson KJ, Peggs KS. Evidence for clinical activity of artesunate in multidrug-resistant herpes simplex infection following HSCT. Bone Marrow Transplant 2012;47(11):1482.

[28] Kaptein SJF, Efferth T, Leis M, Rechter S, Auerochs S, Kalmer M, et al. The anti-malaria drug artesunate inhibits replication of cytomegalovirus in vitro and in vivo. Antiviral Res 2006;69(2):60-9.

[29] Drouot E, Piret J, Boivin G. Artesunate demonstrates in vitro synergism with several antiviral agents against human cytomegalovirus. Antivir Ther 2016:21(6):535-9.

[30] Shapira MY, Resnick IB, Chou S, Neumann AU, Lurain NS, Stamminger T, et al. Artesunate as a potent antiviral agent in a patient with late drug-resistant cytomegalovirus infection after hematopoietic stem cell transplantation. Clin Infect Dis 2008;46(9):1455-7.

[31] Germi R, Mariette C, Alain S, Lupo J, Thiebaut A, Brion JP, et al. Success and failure of artesunate treatment in five transplant recipients with disease caused by drug-resistant cytomegalovirus. Antiviral Res 2014;101:57-61.

[32] Stuehler C, Stüssi G, Halter J, Nowakowska J, Schibli A, Battegay M, et al. Combination therapy for multidrug-resistant cytomegalovirus disease. Transpl Infect Dis 2015;17(5):751-5.

[33] Wolf DG, Shimoni A, Resnick IB, Stamminger T, Neumann AU, Chou S, et al. Human cytomegalovirus kinetics following institution of artesunate after hematopoietic stem cell transplantation. Antiviral Res 2011;90(3):183-6.

[34] Barger-Kamate B, Forman M, Sangare CO, Haidara ASA, Maiga H, Vaidya D, et al. Effect of artemether-lumefantrine (Coartem) on cytomegalovirus urine viral load during and following treatment for malaria in children. J Clin Virol 2016;77:40-5.

[35] Gantt S, Huang M-L, Magaret A, Bunts L, Selke S, Wald A, et al. An artesunate-containing antimalarial treatment regimen did not suppress cytomegalovirus viremia. J Clin Virol 2013;58(1):276-8.

[36] Gignoux E, Azman AS, de Smet M, Azuma P, Massaquoi M, Job D, et al. Effect of artesunate-amodiaquine on mortality related to Ebola virus disease. N Engl J Med 2016;374(1):23-32.

[37] De Cremer K, Lanckacker E, Cools TL, Bax M, De Brucker K, Cos P, et al. Artemisinins, new miconazole potentiators resulting in increased activity against Candida albicans biofilms. Antimicrob Agents Chemother 2015:59(1):421-6.

[38] Gautam P, Upadhyay SK, Hassan W, Madan T, Sirdeshmukh R, Sundaram CS, et al. Transcriptomic and proteomic profile of Aspergillus fumigatus on exposure to artemisinin. Mycopathologia 2011;172(5):331-46.

[39] Li B, Yao Q, Pan X-C, Wang N, Zhang R, Li J, et al. Artesunate enhances the antibacterial effect of $\{$ beta\}-lactam antibiotics against Escherichia coli by increasing antibiotic accumulation via inhibition of the multidrug efflux pump system AcrAB-TolC. J Antimicrob Chemother 2011;66(4): 769-77.

[40] Li B, Zhang R, Li J, Zhang L, Ding G, Luo P, et al. Antimalarial artesunate protects sepsis model mice against heat-killed Escherichia coli challenge by decreasing TLR4, TLR9 mRNA expressions and transcription factor NF-kappa B activation. Int Immunopharmacol 2008;8(3):379-89.

[41] Jiang W, Li B, Zheng X, Liu X, Pan X, Qing R, et al. Artesunate has its enhancement on antibacterial activity of $\beta$-lactams via increasing the 
antibiotic accumulation within methicillin-resistant Staphylococcus aureus (MRSA). J Antibiot 2013;66(6):339-45.

[42] Jiang W, Li B, Zheng X, Liu X, Cen Y, Li J, et al. Artesunate in combination with oxacillin protect sepsis model mice challenged with lethal live methicillin-resistant Staphylococcus aureus (MRSA) via its inhibition on proinflammatory cytokines release and enhancement on antibacterial activity of oxacillin. Int Immunopharmacol 2011;11(8):1065-73.

[43] Feng J, Shi W, Zhang S, Sullivan D, Auwaerter PG, Zhang Y. A drug combination screen identifies drugs active against amoxicillin-induced round bodies of in vitro Borrelia burgdorferi persisters from an FDA Drug Library. Front Microbiol 2016;7:743.

[44] Lantos PM, Auwaerter PG, Wormser GP. A systematic review of Borrelia burgdorferi morphologic variants does not support a role in chronic Lyme disease. Clin Infect Dis 2014;58(5):663-71.

[45] Puri BK, Hakkarainen-Smith JS, Monro JA. The effect of artesunate on short-term memory in Lyme borreliosis. Med Hypotheses 2017;105:4-5.

[46] Blazquez AG, Fernandez-Dolon M, Sanchez-Vicente L, Maestre AD, Gomez-San Miguel AB, Alvarez M, et al. Novel artemisinin derivatives with potential usefulness against liver/colon cancer and viral hepatitis. Bioorg Med Chem 2013;21(14):4432-41.

[47] Kast RE, Boockvar JA, Brüning A, Cappello F, Chang W-W, Cvek B, et al. A conceptually new treatment approach for relapsed glioblastoma: coordinated undermining of survival paths with nine repurposed drugs (CUSP9) by the international initiative for accelerated improvement of glioblastoma care. Oncotarget 2013;4(4):502-30.

[48] Reiter C, Fröhlich T, Zeino M, Marschall M, Bahsi H, Leidenberger M, et al. New efficient artemisinin derived agents against human leukemia cells, human cytomegalovirus and Plasmodium falciparum: 2 nd generation 1,2,4-trioxane-ferrocene hybrids. Eur J Med Chem 2015;97:164-72.

[49] Wang J, Zhang J, Shi Y, Xu C, Zhang C, Wong YK, et al. Mechanistic investigation of the specific anticancer property of artemisinin and its combination with aminolevulinic acid for enhanced anticolorectal cancer activity. ACS Cent Sci 2017;3(7):743-50.

[50] Wang X, Du Q, Mao Z, Fan X, Hu B, Wang Z, et al. Combined treatment with artesunate and bromocriptine has synergistic anticancer effects in pituitary adenoma cell lines. Oncotarget 2017;8:45874-87.

[51] Dong H-Y, Wang Z-F. Antitumor effects of artesunate on human breast carcinoma MCF-7 cells and IGF-IR expression in nude mice xenografts. Chin J Cancer Res 2014;26(2):200-7.

[52] Efferth T. From ancient herb to modern drug: artemisia annua and artemisinin for cancer therapy. Semin Cancer Biol 2017.

[53] Roh J-L, Kim EH, Jang H, Shin D. Nrf2 inhibition reverses the resistance of cisplatin-resistant head and neck cancer cells to artesunate-induced ferroptosis. Redox Biol 2017;11:254-62.
[54] Kelter G, Steinbach D, Konkimalla VB, Tahara T, Taketani S, Fiebig H-H, et al. Role of transferrin receptor and the $\mathrm{ABC}$ transporters $\mathrm{ABCB} 6$ and $\mathrm{ABCB} 7$ for resistance and differentiation of tumor cells towards artesunate. PloS One 2007;2(8):e798.

[55] Berger TG, Dieckmann D, Efferth T, Schultz ES, Funk J-O, Baur A, et al. Artesunate in the treatment of metastatic uveal melanoma - first experiences. Oncol Rep 2005;14(6):1599-603.

[56] Zhang Z-Y, Yu S-Q, Miao L-Y, Huang X-Y, Zhang X-P, Zhu Y-P, et al. [Artesunate combined with vinorelbine plus cisplatin in treatment of advanced non-small cell lung cancer: a randomized controlled trial]. Zhong Xi Yi Jie He Xue Bao 2008;6(2):134-8.

[57] Krishna S, Ganapathi S, Ster IC, Saeed MEM, Cowan M, Finlayson C, et al. A randomised, double blind, placebo-controlled pilot study of oral artesunate therapy for colorectal cancer. EBio Med 2015;2(1):82-90.

[58] von Hagens C, Walter-Sack I, Goeckenjan M, Osburg J, StorchHagenlocher B, Sertel S, et al. Prospective open uncontrolled phase I study to define a well-tolerated dose of oral artesunate as add-on therapy in patients with metastatic breast cancer (ARTIC M33/2). Breast Cancer Res Treat 2017;164(2):359-69.

[59] Jansen FH, Adoubi I, Kouassi Comoe JC, Cnodder DE, Jansen T, Tschulakow N, et al. First study of oral Artenimol-R in advanced cervical cancer: clinical benefit, tolerability and tumor markers. Anticancer Res 2011;31(12):4417-22.

[60] Hou L, Huang H. Immune suppressive properties of artemisinin family drugs. Pharmacol Ther 2016;166:123-7.

[61] Hou L-F, He S-J, Li X, Wan C-P, Yang Y, Zhang X-H, et al. SM934 treated lupus-prone NZB $\times$ NZW F1 mice by enhancing macrophage Interleukin10 production and suppressing pathogenic T cell development. PLoS ONE 2012;7(2):e32424 [Sawalha AH, editor].

[62] Wang J-X, Tang W, Shi L-P, Wan J, Zhou R, Ni J, et al. Investigation of the immunosuppressive activity of artemether on T-cell activation and proliferation. Br J Pharmacol 2007;150(5):652-61.

[63] Jiang W, Cen Y, Song Y, Li P, Qin R, Liu C, et al. Artesunate attenuated progression of atherosclerosis lesion formation alone or combined with rosuvastatin through inhibition of pro-inflammatory cytokines and proinflammatory chemokines. Phytomedicine 2016;23(11):1259-66.

[64] Shi J-Q, Zhang C-C, Sun X-L, Cheng X-X, Wang J-B, Zhang Y-D, et al. Antimalarial drug artemisinin extenuates amyloidogenesis and neuroinflammation in APPswe/PS1dE9 transgenic mice via inhibition of nuclear factor- $\kappa \mathrm{B}$ and NLRP3 inflammasome activation. CNS Neurosci Ther 2013;19(4):262-8.

[65] Yu Q, Jin H. Artesunate in treatment of dermatosis; 1997 [cited 2017 Sep 5; available from: http://www.en.cnki.com.cn/Article_en/ CJFDTOTAL-BANG705.014.htm]. 